\title{
RANCANG BANGUN MOLD UNTUK PROSES TERMOFORMING PROSTHETIC BELOW KNEE (B/K)
}

\author{
Bambang Waluyo F., Aris Aryanto, Tri Widodo Besar R. \\ Teknik Mesin Universitas Muhammadiyah Surakarta \\ Jl. A. Yani Pabelan Tromos Pos I Pabelan, Kartasura \\ Email: bambang_waluyo@ums.id
}

\begin{abstract}
ABSTRAK
Industri semakin berkembang, kebutuhan terhadap plastik pun semakin bertambah. Akan tetapi, dalam aplikasi proses pembentukan plastik sering mengalami kendala. Salah satunya adalah penyusutan. Penyusutan sering terjadi pada proses pembentukan plastik, terutama pembentukan dengan sistem mechanical thermoforming. Sehingga perlu dianalisis hal-hal yang menyebabkan penyusutan pada produk yang dihasilkan. Beberapa hal yang diidentifikasi mempengaruhi terjadinya penyusutan adalah bentuk mold, temperatur, dan jenis plastik yang digunakan.

Metode penelitian yang digunakan adalah membuat alat uji mechanical thermoforming dan membuat mold yang akan digunakan untuk menganalisis penyusutan. Mold yang digunakan ada 2 macam, yaitu mold telapak kaki atas dan mold telapak kaki bawah. Selain variasi pada mold, analisis juga ditujukan pada temperatur plastik polypropylene (PP) dan plastik PVC yang akan diproses. Variasi temperatur yaitu: $100^{\circ} \mathrm{C}, 120^{\circ} \mathrm{C}$, dan $140^{\circ} \mathrm{C}$. Sedangkan jenis plastik yang diujikan adalah plastik polypropylene (PP) dan plastik PVC.

Dari data hasil pengujian dan pembahasan pada proses mechanical thermoforming untuk plastik polypropylene (PP) dengan ketebalan 1,0 mm tidak dapat dianalisis persentase penyusutan yang terjadi karena sifat viskos pada plastik rendah. Pada plastik jenis PP ini meskipun membentuk pola, tetapi tidak sempurna. Bahan plastik $P P$ setelah proses penekanan dengan temperatur $100^{\circ} \mathrm{C}-120^{\circ} \mathrm{C}$ plastik tidak mengalami pemuaian yang cukup baik, karena plastik masih bersifat elastik. Pada temperatur $140^{\circ} \mathrm{C}$ plastik mengalami pemuaian, tetapi saat proses penekanan plastik mengalami bentuk pola yang tidak sempurna, karena temperatur terlalu tinggi. Sedangkan pada plastik PVC didapatkan hasil bahwa pada mold telapak kaki atas dengan ketinggian $2 \mathrm{~cm}$ dan tebal plastik 1,0 $\mathrm{mm}$ menghasilkan persentase penyusutan rata-rata 7,85\% dengan temperatur $100^{\circ} \mathrm{C}, 9,80 \%$ dengan temperatur $120^{\circ} \mathrm{C}$ dan $12,11 \%$ dengan temperatur $140^{\circ} \mathrm{C}$. Pada mold telapak kaki bawah dengan ketinggian $2 \mathrm{~cm}$ dan tebal plastik 1,0 $\mathrm{mm}$ menghasilkan persentase penyusutan rata-rata 10,01\% dengan temperatur $100^{\circ} \mathrm{C}, 10,96 \%$ dengan temperatur $120^{\circ} \mathrm{C}$ dan $12,08 \%$ dengan temperatur $140^{\circ} \mathrm{C}$.
\end{abstract}

Kata Kunci: Mechanical thermoforming, penyusutan plastik, mold

\begin{abstract}
The growing of industry has the effect to the increase of plastic need. However, the application of plastic forming process often experiences constraints. One of them is depreciation. Depreciation often occurs in the plastic forming process, especially
\end{abstract}


forming with mechanical thermoforming system. So it is necessary to analyze the things that cause shrinkage on the product. Some of the things that are identified to influence the shrinkage are the molds, temperatures and types of used plastics.

The used method is to make mechanical thermoforming test and make mold which will be used to analyze depreciation. There are 2 kinds of molds, namely upper foot sole mold and bottom foot sole mold. In addition to the variations of the mold, the analysis is also aimed at the temperature of polypropylene plastic (PP) and PVC plastic which will be processed. The temperature variations are $100^{\circ} \mathrm{C}, 120^{\circ} \mathrm{C}$ and $140^{\circ} \mathrm{C}$ and the types of plastics that are tested is polypropylene plastic (PP) and PVC plastic.

The results show that on mechanical thermoforming process for polypropylene (PP) plastic with $1.0 \mathrm{~mm}$ thickness, the percentage of shrinkage can not be analyzed because of the low viscous nature of plastic. PP type plastic can form a pattern, but not perfect. $P P$ plastic material does not experience a good expansion after pressing process with $100^{\circ} \mathrm{C}-120^{\circ} \mathrm{C}$ plastic temperature. This is because the plastic is still elastic. At $140^{\circ} \mathrm{C}$, the plastic undergoes expansion, but when the plastic pressing process, it undergoes an imperfect pattern. The reason is the temperature is too high. Meanwhile for the PVC plastic, it was found that in the upper foot sole mold with height of $2 \mathrm{~cm}$ and $1.0 \mathrm{~mm}$ plastic thickness, the percentages of shrinkage average are $7.85 \%$ with temperature $100^{\circ} \mathrm{C}, 9.80 \%$ with temperature $120^{\circ} \mathrm{C}$ and $12.11 \%$ with temperature of $140^{\circ} \mathrm{C}$. In the bottom foot sole mold with $2 \mathrm{~cm}$ height and $1.0 \mathrm{~mm}$ plastic thickness, the percentages of shrinkage average are $10.01 \%$ with temperature $100^{\circ} \mathrm{C}, 10.96 \%$ with temperature $120^{\circ} \mathrm{C}$ and $12.08 \%$ with temperature $140^{\circ} \mathrm{C}$.

\section{Keywords: Mechanical thermoforming, plastic shrinkage, mold}

\section{PENDAHULUAN}

Adanya kecenderungan yang terus naik setiap tahunnya atas penderita kecacatan yang mengalami amputasi di Indonesia yang mana data pasiennya dapat diwakili dari Rumah Sakit Orthopedi (RSO) Prof. Dr. Soeharso Surakarta, yang merupakan rumah sakit rujukan orthopedi yang ada di Indonesia. Pada akhir tahun 2006 menunjukkan data terjadinya kasus amputasi anggota gerak bawah kaki adalah sebesar $25 \%$ per tahunnya. Selama waktu antara tahun 2005 sampai dengan tahun 2006, permintaan berbagai prothese ataupun orthese yang dikerjakan oleh Unit Kerja Instalasi Prothese dan Orthese Rumah Sakit Orthopedi Surakarta rata-rata sebanyak 60 unit per bulannya [1].

Selama ini prothese yang diproduksi baik yang dihasilkan oleh Rumah Sakit Orthopedi atau industri kecil yang ada di Kota Solo masih mengutamakan fungsinya sebagai kosmetik. Sedangkan prothese kaki yang berfungsi sebagai alat bantu (artificial) dalam manjalankan aktivitas sehari-hari masih belum terakomodasi secara baik. Hal ini terlihat pada pengguna prothese kaki pada saat melakukan langkah berjalan sacara normal masih terlihat adanya phase berjalan yang kurang baik yang diakibatkan oleh dampak kecacatan, terlebih bilamana berjalan naik dan menuruni anak tangga yang cukup tinggi ataupun turun dari bus kota. Atas gambaran kondisi ini bahwa prothese kaki yang ada masih belum memenuhi aspek fungsinya secara baik yang antara lain mampu menopang berat tubuh yang nyaman, aman, stabil, kuat, dan ringan.

Pembuatan prothese kaki memiliki tingkat kesulitan yang cukup tinggi dan waktu dibutuhkan untuk pemesanannya cukup lama. Terlebih untuk proses pembuatan prothese kaki di bawah lutut memerlukan bayak sekali bagian komponen pendukung yang meliputi korset paha, soket betis, knee, adaptor dan SACH (Solid Ankle Cushioned Heel) foot. Lamanya waktu menunggu bagi pasien atas prothese yang diperlukan waktu sampai satu bulan dari 
hari setelah pengukuran, di sisi lain penggunaan dari lamanya jangka waktu penggunaan komponen produk prothese kaki cukup pendek. Rata-rata komponen bertahan sekitar tiga tahun, pendekatan life cycle komponen produk prothese kaki diakibatkan oleh frekuensi gerakan aktivitas penggunaan sehari-hari.

Hasil kajian dari penelitian yang telah dilakukan oleh Lobes Herdiman dan Fabianus Suryono (2007) menunjukkan bahwa proses pembuatan prothese kaki di lingkungan Rumah Sakit Orthopedi dan instalasi kecil yang ada di kota Solo masih sangat sederhana. Mereka mengedepankan proses pembuatan handcrafting dan teknologi proses manufaktur yang digunakan masih bersifat konvensional [1,2]. Proses pembuatan prothese kaki yang dilakukan secara handcrafting muncul beberapa permasalahan yang dihadapi yaitu lamanya waktu menunggu untuk pemesanan dan lamanya waktu penyesuaian antara prothese dengan pasien setelah menggunakan produk yang dikerjakan. Bantuan teknologi telah dimungkinkan untuk dimanfaatkan proses perencanaan dan perancangan produk dari beberapa bagian komponen prothese kaki kususnya, melalui pemanfaatan teknologi thermoforming banyak hal yang dapat dikerjakan yaitu meningkatkan ketepatan ukuran produk, mampu keterulangan dalam pembuatan secara baik dan kesederhanaan proses penyesuaian produk. Kelebihan yang ditawarkan oleh proses thermoforming pembuatan prothese kaki adalah memperbaiki rancangan, meningkatkan kenyamanan pengguna produk, kemudian dalam pabrikasi dan penyesuaian pada produk atau komponen prothese.

Berdasarkan gambaran di atas, proses pembuatan prothese kaki yang ada di Indonesia sudah waktunya untuk melakukan terobosan dalam menggunakan teknologi thermoforming, agar dapat meningkatkan dalam pembuatan prothese kaki melalui upaya peningkatan adaptasi pengembangan teknologi. Adanya pengembangan penguasaan teknologi pembuatan prothese kaki ini akan memperkuat industri kecil yang ada di Kota Solo secara khususnya dengan memiliki daya saing yang cukup baik. Sekaligus mampu mempercepat dalam pembuatan prothese kaki yang dipesan oleh pasien, dan terutama bagi negara Indonesia tidak lagi ketergantungan terus akan produk impor, meskipun pasar di Indonesia sangat menjanjikan bilamana diikuti dengan daya beli masyarakat. Sama halnya juga pada pasien yang cacat dikarenakan sesuatu hal yang harus mengalami amputasi dan tidak punya alternatif penawaran lain atas prothese kaki yang ada.

Tantangan pada penelitian ini adalah difokuskan pada mechanical thermoforming, pembuatan mold dengan gips dan komponen SACHfoot dengan plastik. Kemudian bahan yang digunakan dalam penelitian adalah dari plastik dengan menggunakan proses thermoforming. Diharapkan penelitian ini dapat meningkatkan rancangan prothese kaki dengan bentuk yang komponen yang lebih costumermize dan dapat dikembangkan secara masal produk tersebut.

\section{METODOLOGI}

\section{Pembuatan Alat Uji}

Pembuatan alat uji, yaitu mechanical thermoforming menggunakan banyak material dan peralatan [4-8]. Bahan dan peralatan yang digunakan akan dijabarkan pada halaman berikutnya. Selain alat dan bahan yang digunakan, proses pembuatan mold juga akan dijabarkan di sini. Sketsa alat uji mechanical thermoforming dapat dilihat pada gambar 1 .

\section{Peralatan yang digunakan untuk membuat alat uji}

1. Mesin las listrik

Mesin las listrik berguna untuk mengelas rangka mold, rangka heater, dan rangka penjepit plastik.

2. Mesin gerinda tangan

Mesin gerinda tangan berguna untuk meratakan permukaan hasil pengelasan, misalnya 
pada permukaan rangka setelah disambung dengan las agar permukaan lebih halus sehingga tampak rapi.

3. Mesin bor

Mesin bor berguna untuk membuat lubang pada rangka mold, rangka dudukan heater dan rangka penjepit plastik.

4. Satu set tool

Satu set tool berguna untuk alat bantu pembuatan rangkaian mechanical thermoforming.

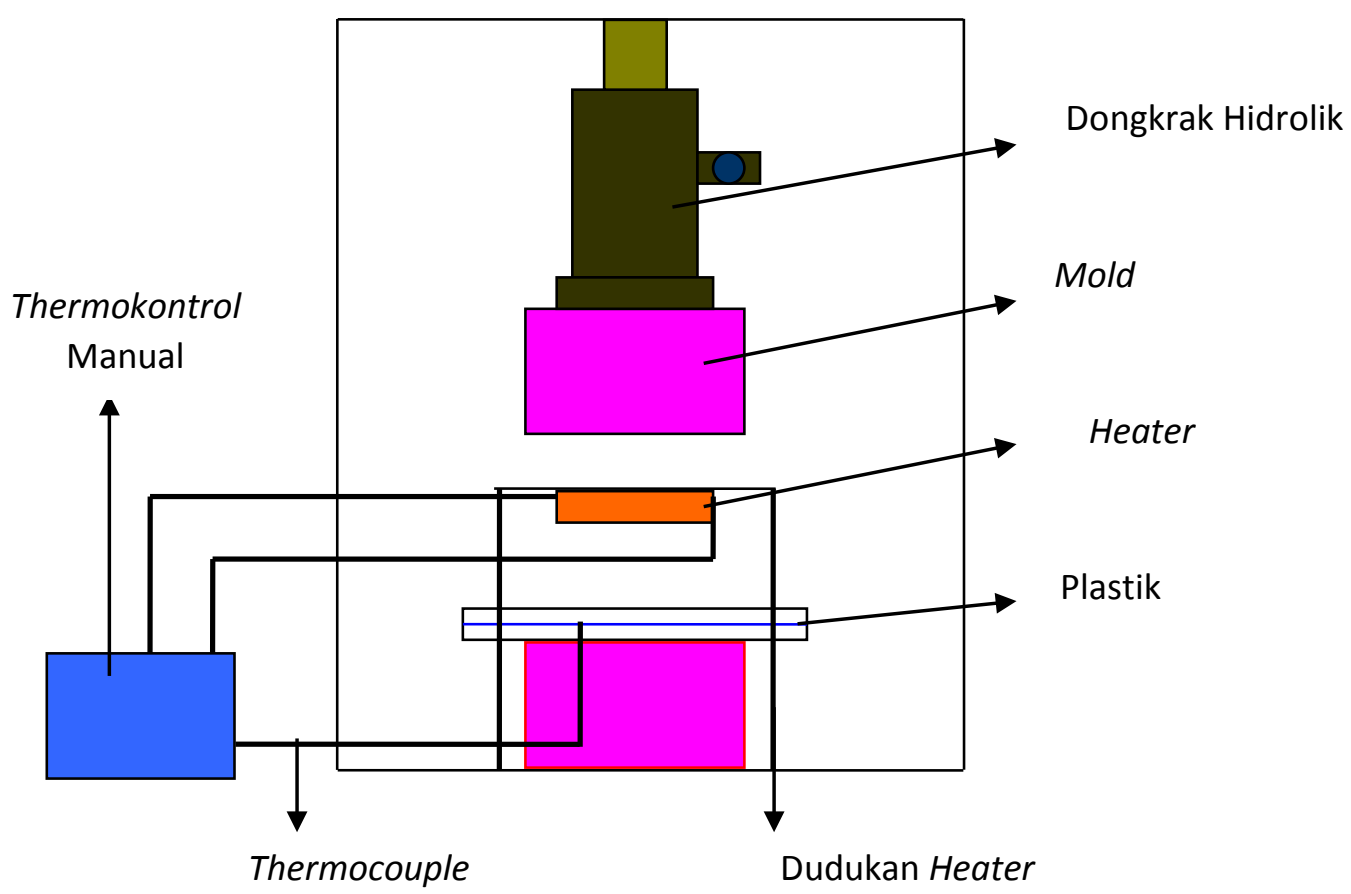

Gambar 1. Sket alat uji mechanical thermoforming

\section{Bahan yang digunakan untuk membuat alat uji}

1. Besi siku

Besi siku berguna sebagai rangka mold, rangka dudukan heater dan rangka penjepit plastik.

2. Seng

Seng digunakan untuk membuat penutup pada rangka mold.

3. Alat pengikat

Mur baut berguna sebagai pengikat. Misalnya antara mold positif dengan penekan dongkrak dan antara penjepit plastik dengan mold negatif.

\section{Pembuatan mold [3-8]}

Mold dibuat dari gipsum dengan campuran gips dan air (PDAM). Komposisi pencampuran antara gips sebesar 70\% dan air (PDAM) sebesar 30\% diaduk sampai kental. Proses berikutnya adalah gipsum dituang ke dalam cetakan, kemudian di-finishing sampai berbentuk menyerupai pola kaki. Adapun bentuk mold tersebut adalah berbentuk $1 / 2$ kaki, 2 mold positif dan 2 mold negatif. Model 4 mold dapat dilihat pada gambar 2. 


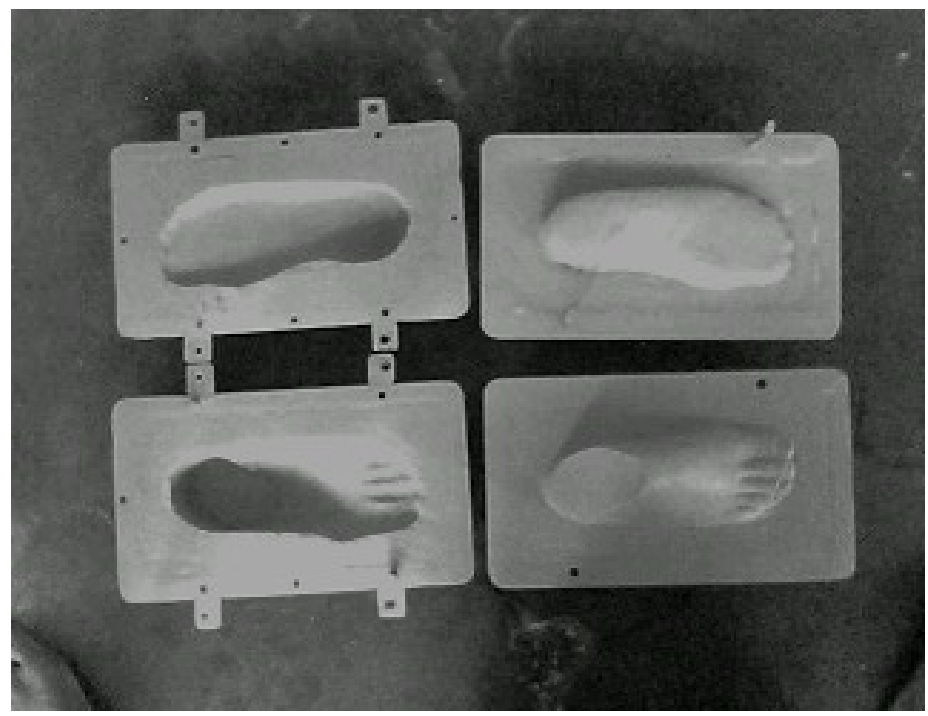

Gambar 2. Dua mold positif dan dua mold negatif

\section{Peralatan yang digunakan dalam penelitian}

Ada beberapa peralatan yang digunakan dalam penelitian, di antaranya adalah:

1. Pemanas atau heater

Pemanas yang digunakan adalah heater dengan daya 1000 Watt. Alat ini digunakan untuk memanaskan lembaran plastik dari salah satu sisi saja yaitu sebelah atas.

2. Thermocontrol

Thermocontrol yang digunakan adalah thermocontrol manual, fungsinya untuk mengetahui temperatur bahan plastik, kemampuan panas hingga mencapai $400^{\circ} \mathrm{C}$ dan kuat arus 15 Ampere.

3. Dongkrak hidrolik

Dongkrak hidrolik berfungsi sebagai alat penekan bahan lembaran plastik agar terbentuk sesuai dengan bentuk mold. Dongkrak hidrolik memiliki daya tekan beban sampai 20 Ton.

4. Gelas ukur dan air (PDAM)

Gelas ukur dan air berfungsi sebagai alat pengukur cairan, dengan alat ini dapat diketahui besarnya simpangan penyusutan pada penelitian yang dilakukan.

\section{Bahan penelitian}

1. Lembaran plastik PVC dan PP

Bahan penelitian didapat dari toko Morodadi yang berlokasi di Surakarta. Bahan yang digunakan ini adalah lembaran plastik polypropylene (PP) ketebalan $1.0 \mathrm{~mm}$ dengan ukuran $(40 \mathrm{x} 15) \mathrm{cm}$ dan lembaran plastik PVC ketebalan $1.0 \mathrm{~mm}$ dengan ukuran $(40 \mathrm{x}$ 15) $\mathrm{cm}$. Alasan pemilihan bahan ini adalah karena merupakan jenis plastik yang mudah dibentuk, banyak dipasaran, ringan, dan modern.

2. Gibs

3. Resin

4. Katalis

Bahan ini berfungsi sebagai pengeras, apabila dicampur dengan campuran resin.

5. Cat warna

\section{Langkah pengerjaan penelitian}

Tahapan-tahapan yang akan dilakukan adalah: 
1. Persiapan

Sebelum percobaan dimulai, perlu disiapkan semua bahan dan peralatan pendukung yang akan digunakan. Kertas dan alat tulis yang akan digunakan untuk mencatat semua data hasil pengujian harus juga disiapkan.

2. Pemotongan dan pemasangan plastik

Lembaran plastik dipotong dengan ukuran 40x25 cm, sesuai dengan ukuran penjepit plastiknya dan kemudian plastik dipasang pada mold negatif setelah itu plastik dijepit. Pemasangan dapat dilihat pada gambar 3.

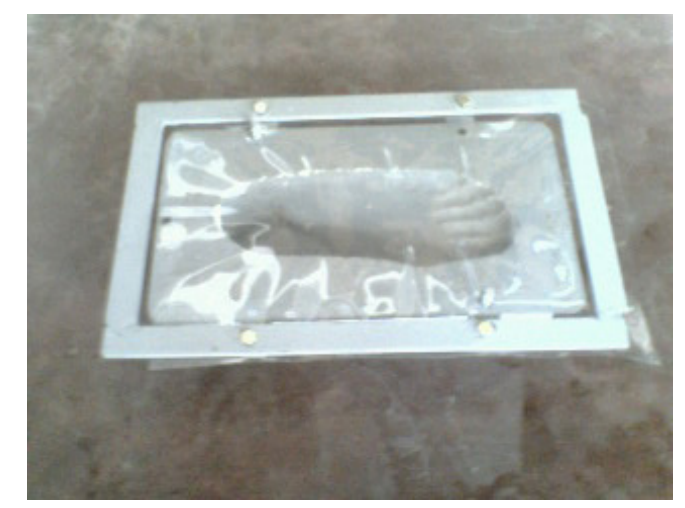

Gambar 3 Pemasangan plastik pada penjepit

3. Pemasangan kabel pada pemasangan pada mesin

Plastik yang sudah terpasang pada mold negatifdan sudah dijepit, setelah itu thermocouple diletakkan pada bagian bawah plastik tersebut agar dapat terdeteksi temperatur plastik pada thermocouple manual.

4. Pemasangan dongkrak hidrolik pada mold

Pemasangan dongkrak hidrolik pada mold positif diletakkan di atas cetakan dan penekanan mold dengan arah ke bawah.

5. Pemrosesan bahan

Bahan yang sudah dijepit kemudian dipanasi dengan menggunakan heater dengan temperatur yang sudah ditentukan disertai pemasangan thermocouple manual untuk mengetahui temperatur pada bahan. Setelah tercapai temperatur yang sudah ditentukan, kemudian mold positif sampai posisi menekan bahan. Bersamaan dengan penekanan dongkrak hidrolik, sehingga proses penekanan plastik oleh mold dapat berlangsung. Setelah plastik terbentuk sesuai bentuk mold, maka dilakukan pendinginan dengan udara agar bentuk produk yang dihasilkan tidak berubah. Setelah proses mechanical thermoforming sudah selesai, dongkrak dapat dinaikan lagi ke posisi semula dan produk hasil mechanical thermoforming dapat dikeluarkan.

\section{Cara memperoleh data}

Untuk mengidentifikasi penyusutsn yang terjadi pada lembaran plastik polypropylene (PP) dan PVC dari hasil proses mechanical thermoforming adalah Proses mechanical thermoforming pada plastik polypropylene (PP) dan PVC dengan variasi temperatur. Sehingga didapatkan 18 pengujian plastik PVC dan 18 pengujian plastik polypropylene (PP) maka masing-masing percobaan pada kondisi yang sama sebanyak 3 kali. Adapun yang akan dianalisis pada pengujian ini adalah:

1. Persentase penyusutan terhadap volume pada plastik hasil cetak pada proses mechanical thermoforming.

2. Temperatur yang paling sesuai pada tiap-tiap variasinya agar didapatkan persentase penyusutan yang paling kecil. 
Setelah data yang dibutuhkan didapat, kemudian dianalisis penyebab-penyebab dari terjadinya penyusutan tersebut berdasarkan teori yang ada.

\section{HASIL PENELITIAN DAN PEMBAHASAN}

\section{Pengujian Mold Menggunakan Plastik Polypropylene (PP)}

Pada gambar 4 ditunjukan foto hasil dari proses mechanical thermoforming. Pada plastik jenis PP ini tebal yang digunakan adalah $1.0 \mathrm{~mm}$ sehingga material yang akan diproses mechanical thermoforming sangat tebal. Plastik jenis ini, dengan menggunakan proses mechanical thermoforming bertemperatur $100^{\circ} \mathrm{C}, 120^{\circ} \mathrm{C}$ dan $140^{\circ} \mathrm{C}$ sering terjadi pola tidak sempurna dan kerut. Pada plastik jenis PP ini tidak dapat dianalisis persentase penyusutan yang terjadi, meskipun membentuk pola seperti bentuk mold karena sifat viscos pada plastik PP ini rendah. Bahan plastik PP setelah mengalami proses penekanan dengan temperatur $100^{\circ} \mathrm{C}-120^{\circ} \mathrm{C}$ plastik tidak mengalami pemuaian yang cukup baik, karena itu plastik masih bersifat elastik. Pada temperatur $140^{\circ} \mathrm{C}$ plastik mengalami pemuaian yang baik, tetapi saat proses penekanan plastik mengalami bentuk pola yang tidak sempurna, karena temperatur terlalu tinggi. Hasil analisis dapat dilihat pada gambar 5 sampai 7

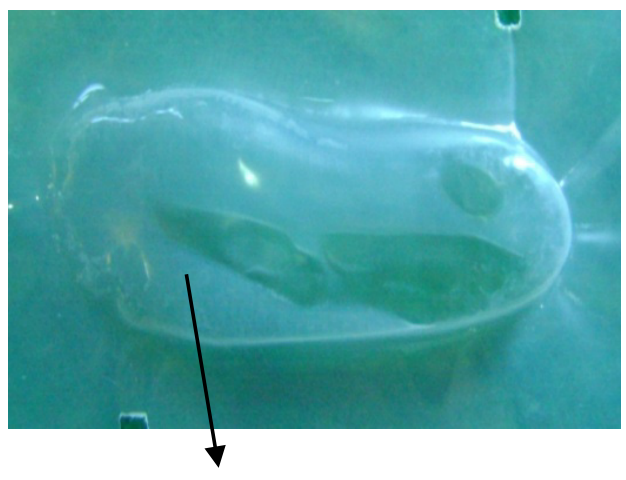

Pola tidak sempurna

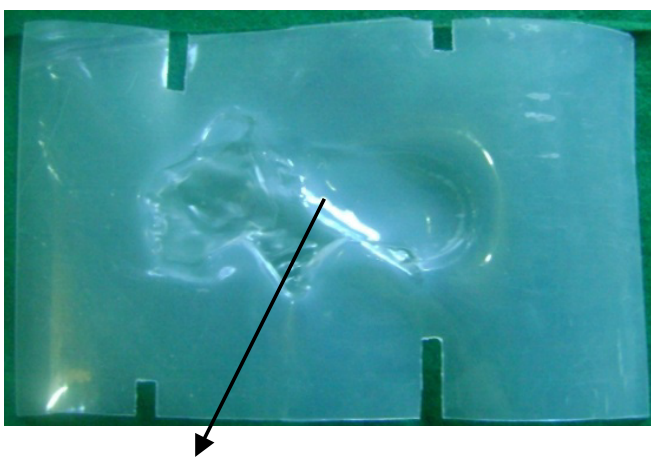

Kerutan

Gambar 4. Foto hasil mechanical thermoforming

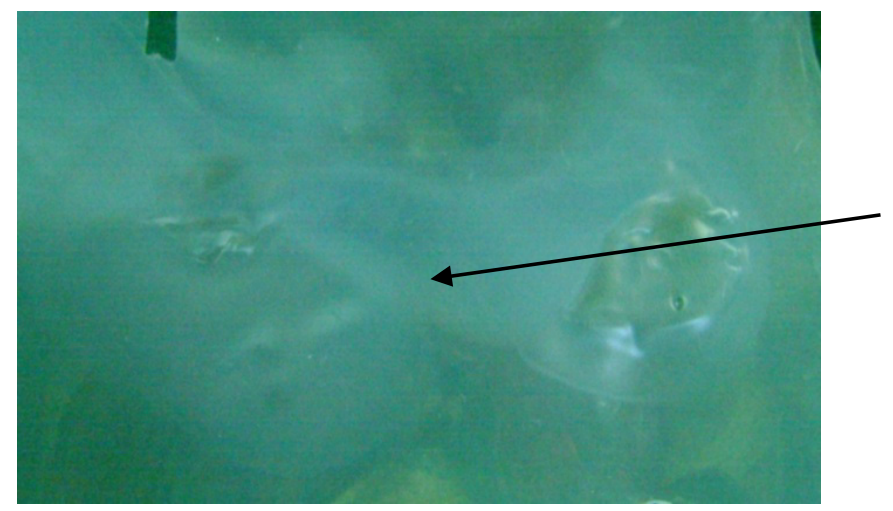

Tidak banyak berubah

(masih datar)

Gambar 5. PP diproses dengan mold telapak kaki atas dan mold telapak kaki bawah temperatur $100^{\circ} \mathrm{C}$ 


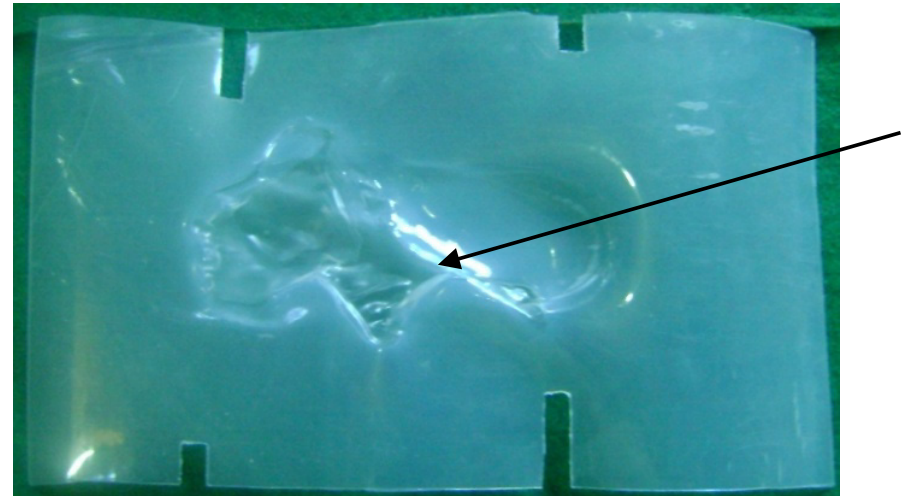

Tidak membentuk

pola

Gambar 6. PP diproses dengan mold telapak kaki atas dan mold telapak kaki bawah temperatur $120^{\circ} \mathrm{C}$

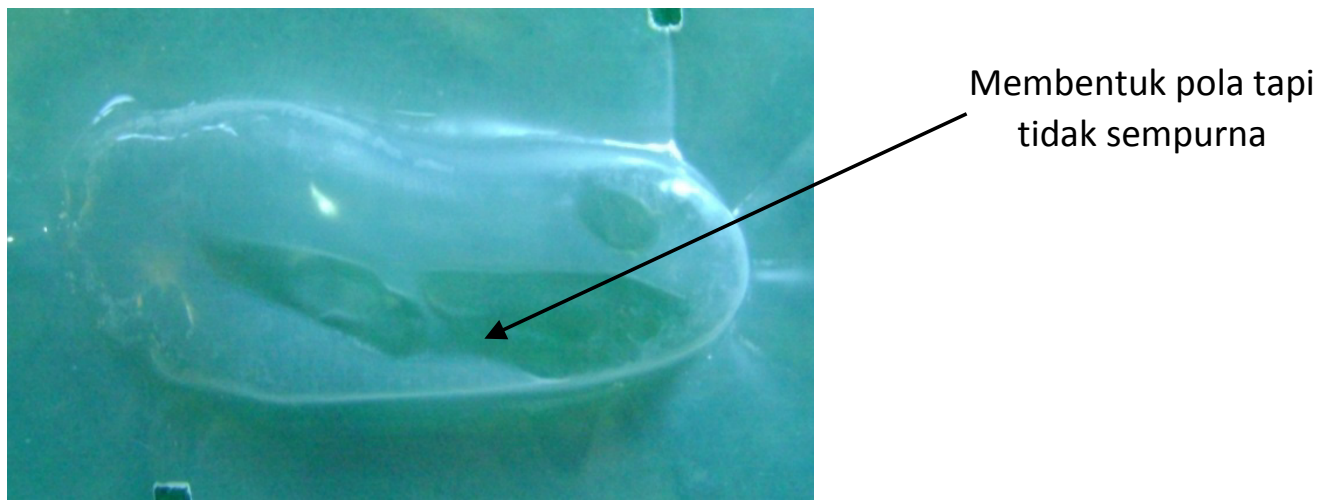

Gambar 7. PP diproses dengan mold telapak kaki atas dan mold telapak kaki bawah temperatur $140^{\circ} \mathrm{C}$

\section{Pengujian Mold Menggunakan Plastic PVC}

Penyusutan adalah cacat perubahan dimensi ukuran pada mold, maka ukuran produknya akan berbeda, yaitu ukuran luar benda kerja akan lebih kecil dibanding dengan ukuran cetakan. Untuk lebih jelasnya dapat dilihat pada gambar 8.

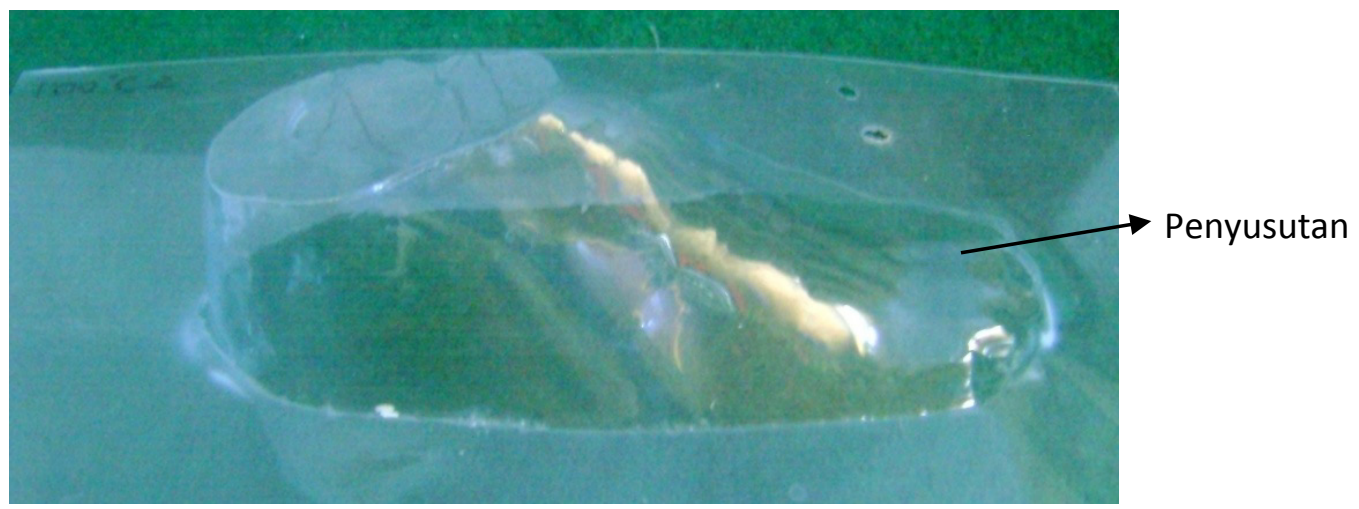

Gambar 8. Contoh penyusutan pada plastik PVC 
ISSN: 1411-4348

\section{Perbandingan Mold Telapak Kaki Atas dan Bawah}

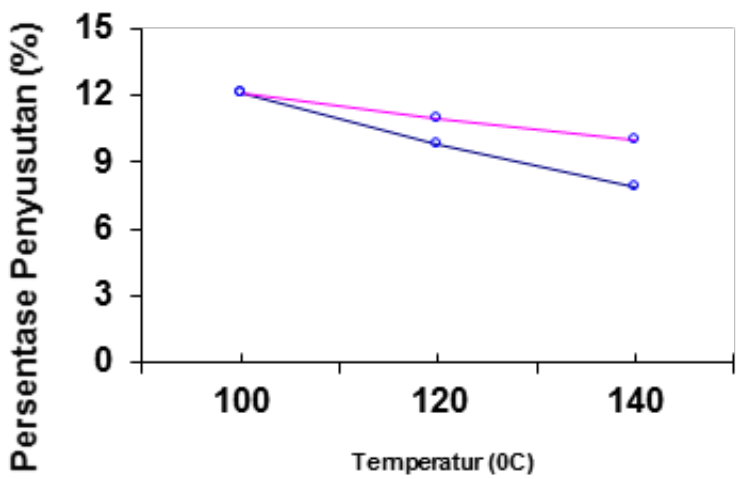

- Telapak Kaki A tas $\rightarrow$ Telapak Kaki Bawah

Gambar 9. Grafik hubungan bentuk mold terhadap persentase penyusutan

Gambar 9 menunjukan hubungan antara perbedaan temperatur terhadap persentase penyusutan ditinjau dari setiap bentuk mold, yaitu mold telapak kaki atas dan mold telapak kaki bawah. Pada semua variasi bentuk mold untuk temperatur $100^{\circ} \mathrm{C}$ persentase penyusutan hampir sama yaitu kurang lebih $12 \%$. Ini terjadi karena pada temperatur tersebut pemuaian plastik belum maksimal, sehingga terjadi penyusutan saat penekanan mold pada proses mechanical thermoforming. Selain itu, pada temperatur tersebut sering terjadi gagal produk dikarenakan pemuaian plastik yang dibutuhkan belum mencukupi, sehingga tidak bisa membentuk pola secara sempurna. Pada semua bentuk mold dari ketinggian $2 \mathrm{~cm}$ semuanya terdapat penyusutan, hal ini terjadi karena tebal plastik PVC adalah 1,0 mm sedangkan pemuaian panjang hanya $1-5,5 \mathrm{~cm}$. Sehingga plastik yang memuai sebenarnya bisa lebih dari $1 \mathrm{~cm}$ tetapi hanya ditekan sampai $1-5,5 \mathrm{~cm}$, maka sisa dari pemuaian plastik yang tidak mulur akan menyebabkan terjadinya penyusutan. Oleh karena itu, pada bentuk mold telapak kaki atas mempunyai persentase penyusutan yang paling rendah dibandingkan dengan bentuk mold telapak kaki bawah.

Semua persentase penyusutan pada mold telapak kaki atas menunjukan antara 7,85\%$12,11 \%$. Sedangkan untuk mold telapak kaki bawah persentase penyusutan cenderung naik antara 10,01\%-12,08\%. Maka mold telapak kaki atas lebih cocok untuk produk yang dihasilkan. Secara umum, untuk kedua bentuk mold dengan beberapa variasi temperatur, persentase penyusutan yang terjadi adalah semakin tinggi temperatur maka nilai penyusutan semakin kecil dan semakin rendah temperatur maka nilai penyusutan paling besar. Dari gambar 9 dapat dianalisis yaitu pada temperatur $140^{\circ} \mathrm{C}$ mempunyai pemuaian yang tepat untuk mold telapak kaki atas dan mold telapak kaki bawah. Ada beberapa faktor yang mempengaruhi mechanical thermoforming, tetapi yang paling utama adalah bentuk ketinggian mold dan temperatur [9-10].

Tidak meratanya temperatur dan bentuk mold ini mengakibatkan perbedaan tekanan yang dibutuhkan. Semakin tinggi temperatur, tegangan yang dibutuhkan semakin kecil, sedangkan tekanan yang diberikan ke plastik sama. Hal inilah yang menyebabkan terjadinya penyusutan. Bagian plastik yang temperaturnya lebih tinggi akan terjadi penyusutan lebih kecil. Sedangkan pada bagian yang temperaturnya lebih rendah dari batas forming tidak membentuk dengan sempurna. Meskipun plastik yang temperaturnya berada pada toleransi forming (pembentukan) lebih banyak, tetapi apabila dibentuk bersama dengan bagian plastik yang berada pada temperatur lebih atau kurang dari toleransi mengakibatkan terjadinya 
penyusutan. Besarnya penyusutan yang terjadi tergantung dari penyebaran temperatur yang terjadi pada plastik tersebut.

\section{KESIMPULAN}

Berdasarkan pembahasan tentang "Analisis Penyusutan Pada Lembaran Plastik Polypropylene (PP) dan Plastik PVC Hasil Proses Mechanical Thermoforming" dapat diambil kesimpulan bahwa:

1. Proses mechanical thermoforming pada plastik polypropylene (PP) dengan ketebalan 1,0 mm tidak dapat dianalisis karena sifat viskos pada material rendah. Sedangkan pada plastik PVC dengan ketebalan 1,0 mm dengan variasi temperatur yaitu mulai dari $100^{\circ} \mathrm{C}, 120^{\circ} \mathrm{C}$, dan $140^{\circ} \mathrm{C}$. Persentase penyusutan paling kecil adalah pada temperatur $140^{\circ} \mathrm{C}$

2. a. Mold dengan model mold telapak kaki atas dan mold telapak kaki bawah cocok untuk plastik PVC dengan ketebalan 1,0 mm dapat dianalisis persentase penyusutanya yang terjadi karena sifat viskos pada material tinggi. Sedangkan pada plastik polypropylene $(\mathrm{PP})$ dengan ketebalan $1,0 \mathrm{~mm}$ hasilnya tidak dapat membentuk pola.

b. Temperatur yang optimal untuk plastik polypropylene (PP) dengan tebal 1,0 mm tidak dapat dianalisis karena hampir semua percobaan rusak atau tidak masuk kriteria. Sedangkan temperatur yang optimal untuk plastik PVC dengan ketebalan $1,0 \mathrm{~mm}$ adalah $140^{\circ} \mathrm{C}$ menghasilkan persentase penyusutan paling kecil, untuk $120^{\circ} \mathrm{C}$ persentase penyusutan lebih besar dari temperatur $140^{\circ} \mathrm{C}$. Kalau temperatur $100^{\circ} \mathrm{C}$ terlalu rendah, sehingga penyusutan semakin tinggi.

\section{DAFTAR PUSTAKA}

[1] Herdiman, L., 2007. Pengembangan Karakteristik Fungsi Prothese Kaki Jenis Above Knee Amputation dengan Teknologi Computer Aided Engineering (CAE). Surakarta: Universitas Sebelas Maret.

[2] Suryono, A.F., 2007. Kajian dalam Pegembangan Rancangan Sach Foot Pengguna Prothese Jenis Below Knee Amputation Berdasarkan Penekanan Biomekanika. Surakarta: Universitas Sebelas Maret.

[3] Combe, E.C., 1992. Pembuatan Cetakan dari Gypsum. Diakses 15 Juni 2009 dari www. google.com/gypsum

[4] Bralla, James, G., 1998. Design for Manufacturability Handbook. McGraw-Hill Companies.

[5] Groover, M. P., 1996. Fundamentals of Modern Manufacturing Materials Processes and Svstem, Prentice-Hall.

[6] Kalpakjian, Serope and Steven R. Schmid, 2003. Manufacturing Process for Engineering Materials, fourh Edition. 1llinois Institute of Technology, Chicago.

[7] Ma'arif, S., 2009. Analisis Warpage Pada Lembaran Plastik Polyethylene (PE) dan Polypropylene (PP) Hasil Proses Vacum Thermoforming. Surakarta: Universitas Muhammadiyah Surakarta.

[8] Schey, J. A., 2000. Introduction to Manufacturing Process, McGraw Hill. 
ISSN: 1411-4348

[9] Saito, S., Surdia, T., 1999. Pengetahuan Bahan Teknik. PT. Pradnya Paramita, Jakarta.

[10] Smith, William F. and Javad Hashemi, 2006. Foundations of Materials science and Engineering, McGraw Hill. 